\title{
Incidence and demographic characteristics of Syrian Civil War-related amputations: A multi-center study
}

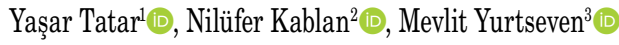 \\ ${ }^{1}$ Department of Sports-Health, Marmara University, Faculty of Sport Sciences, Istanbul, Turkey \\ ${ }^{2}$ Department of Physiotherapy and Rehabilitation, Health Sciences University, Faculty of Health Sciences, Istanbul, Turkey \\ ${ }^{3}$ Istanbul Leprosy, Skin and Venereal Diseases Hospital, Istanbul, Turkey
}

Received: July 16, 2019 Accepted: December 18, 2019 Published online: March 04, 2021

\begin{abstract}
Objectives: The aim of this study was to identify the causes, levels, and rates of amputations performed in civilians during the Syrian Civil War and to present epidemiological data of the amputees.

Patients and methods: Between August 2017 and February 2019, a total of 363 amputations of 307 amputees (266 males, 41 females; mean age $29.9 \pm 13.3$ years; range, 6 to 86 years) were retrospectively analyzed in four prosthesis and orthosis centers managed by an international non-governmental organization and serving to individuals who experienced amputation during Syrian Civil War. Level, etiology, number of amputations and distribution of the amputations by years were investigated.

Results: Of the patients, $25.4 \%$ were under the age of 18 years. A total of $74 \%$ of all amputations were of the lower extremities. Transtibial and transfemoral amputations were the most common amputation levels. Of the amputees, $89.3 \%$ reported the cause of amputation as bombing.

Conclusion: Civil amputations during the Syrian Civil War are different from those in other civil wars due to the high rate of bombing-induced amputations and also the high rate of victims under the age of 18 years. Our study results show a high ratio of both lower and upper extremity amputations in these civilians.
\end{abstract}

Keywords: Amputation, bombing, Syrian Civil War.

Extremity loss is a factor which adversely affects human life physically, psychologically, and vocationally. The causes of amputation in civil life are usually reported as vascular disorders, bone and joint malignancies, traumas and congenital factors, ${ }^{[1]}$ while these factors are replaced by others in regions where the war and terrorism are in effect. Currently, wars can cause injuries that endanger civilians rather than the military personnel. In the past, deaths and injuries on battlefields were primarily due to secondary factors such as hunger, infection, or housing problems; however, they happen directly related to the war itself currently. ${ }^{[2]}$ High-energy explosions constitute a significant part of trauma-induced amputations in regions of terrorism and war. ${ }^{[3]}$ In previous years, most extensive and serious injuries caused by explosive weapons resulted in deaths; however, developing technologies and surgical techniques have increased the survival incidence. ${ }^{[4,5]}$ The decrease in mortality rates has been in parallel with the increase in multiple amputations due to such injuries. ${ }^{[6]}$ The majority of lower extremity amputations (LEAs) occurring in war regions are caused by landmines. ${ }^{[7,8]}$ Most of the studies investigating injuries and amputations in war zones have involved only the military personnel, ${ }^{[8-12]}$ whereas there are few studies including civilians. ${ }^{[13]}$ After the

Corresponding author: Yaşar Tatar, MD. Marmara Üniversitesi Anadolu Hisarı Yerleşkesi, Spor Bilimleri Fakültesi, 34815 Beykoz, İstanbul, Türkiye.

e-mail: ytatar@marmara.edu.tr

Tatar Y, Kablan N, Yurtseven M. Incidence and demographic characteristics of Syrian Civil War-related amputations: A multi-center study. Turk J Phys Med Rehab 2021;67(1):48-55. Presented at the 27" Congress of Physical Medicine and Rehabilitation with International Participation, 17-21 April 2019, Belek, Antalya, Turkey 
onset of the Syrian Civil War, several studies have been conducted in Turkey, mostly involving hosting refugees and injured individuals from Syria. ${ }^{[14-18]}$ In the present study, we aimed to identify the levels, causes, and rates of civilian amputations related to the Syrian Civil War and to document the epidemiological data of civilian amputees.

\section{PATIENTS AND METHODS}

This retrospective study was conducted in prosthesis and orthosis centers located in Istanbul, Reyhanli district of Hatay, and Sanliurfa provinces from Turkey and Jarabulus province of Syria between August 17 $7^{\text {th }}, 2017$ and February 1 ${ }^{\text {st }}, 2019$. These centers managed by an international nongovernmental organization (NGO) were established to provide prosthesis and orthosis services to the Syrians injured during the civil war. The NGO has operated through branches in all cities of Turkey. These branches conducted screening in their provinces and reached Syrian amputees living in the city and camps. Amputees in need of prosthesis were transferred to one of the four centers by the institution. Also, settlements, camps and border gates, which were far away from the centers, were visited and measurement-prosthesis service was provided in these places.

A total of 363 amputations of 307 amputees (266 males, 41 females; mean age $29.9 \pm 13.3$ years; range, 6 to 86 years) were retrospectively analyzed. Hundred and fifty nine amputees who were rehabilitated in these centers for any reason other than the civil war were excluded. The study protocol was approved by the Ethics committee of Marmara University Medical Faculty. The study was conducted in accordance with the principles of the Declaration of Helsinki.

Data including demographic (age, sex, educational level, maritual status, occupation, distribution of the amputations by years etc.) and clinical characteristics (amputation level, cause of amputation, with/out a chronic disease) of the patients were recorded.

\section{Statistical analysis}

Statistical analysis was performed using the IBM SPSS for Windows version 21.0 software (IBM Corp., Armonk, NY, USA). Descriptive data were expressed in mean \pm standard deviation (SD), median (min-max) or number and frequency.

\section{RESULTS}

Baseline demographic and clinical characteristics of the amputees are presented in Table 1. The majority of the amputees (59.9\%) had an educational level of middle school or below (Table 1).

A considerable amount of the amputees (23.1\%) were students and only $10.1 \%$ of them were unemployed before the war (Table 2).

\begin{tabular}{|c|c|c|c|c|c|c|c|c|c|}
\hline \multicolumn{10}{|c|}{$\begin{array}{c}\text { TABLE } 1 \\
\text { Baseline demographic and clinical characteristics of amputees }\end{array}$} \\
\hline & \multicolumn{3}{|c|}{ Single extremity amputation } & \multicolumn{3}{|c|}{ Multiple extremity amputation } & \multicolumn{3}{|c|}{ Total } \\
\hline & $\mathrm{n}$ & $\%$ & Mean \pm SD & $\mathrm{n}$ & $\%$ & Mean \pm SD & $\mathrm{n}$ & $\%$ & Mean \pm SD \\
\hline Amputees & 255 & 83.1 & & 52 & 16.9 & & 307 & 100 & \\
\hline Current age & & & $30.5 \pm 14.3$ & & & $26.6 \pm 10.1$ & & & $29.9 \pm 13.3$ \\
\hline Age of amputees & & & $26.54 \pm 13.7$ & & & $22.5 \pm 10.1$ & & & $25.8 \pm 13.2$ \\
\hline \multicolumn{10}{|l|}{ Sex } \\
\hline Female & & 14.5 & & & 7.7 & & & 13.4 & \\
\hline Male & & 85.5 & & & 92.3 & & & 86.6 & \\
\hline \multicolumn{10}{|l|}{ Educational level } \\
\hline Illiterate & & & & & & & & 7.2 & \\
\hline Pre-school & & & & & & & & 0.7 & \\
\hline Middle school or below & & & & & & & & 59.9 & \\
\hline High school & & & & & & & & 17.3 & \\
\hline University & & & & & & & & 8.2 & \\
\hline Under the age of 18 & & 24.3 & & & 30.8 & & & 25.4 & \\
\hline Married & & 39.2 & & & 50 & & & 56 & \\
\hline Those already using a prosthesis & & 41.6 & & & 63.5 & & & 45.3 & \\
\hline Those with a chronic disease & & 3.2 & & & 1.9 & & & 3 & \\
\hline
\end{tabular}




\begin{tabular}{|c|c|c|}
\hline \multicolumn{3}{|c|}{$\begin{array}{c}\text { TABLE } 2 \\
\text { Pre-war and current occupations of the } \\
\text { amputees }\end{array}$} \\
\hline & Pre-war & Current \\
\hline & $\%$ & $\%$ \\
\hline Student & 23.1 & 10.1 \\
\hline Worker & 21.2 & 7.8 \\
\hline Trades people & 16.3 & 4.2 \\
\hline Housewife & 7.8 & 7.8 \\
\hline Unemployed & 10.1 & 59.9 \\
\hline Others & 21.5 & 10.2 \\
\hline
\end{tabular}

Transtibial amputations (TTAs) and transfemoral amputations (TFAs) were found to be the most common amputation levels with a similar rate to each other in both single extremity amputees and in the total of the amputees (Table 3 ).

Of a total of 363 amputations in 307 amputees, 255 had single extremity, 48 had bilateral extremity, and four had triple extremity amputations. The TTA and TFA were the most common amputation levels (Table 4).

Bombing was reported to be the most common etiology of amputation in $89.3 \%$ of patients (Table 5).

\begin{tabular}{|c|c|c|c|c|c|c|}
\hline \multirow[b]{3}{*}{ Single } & \multicolumn{5}{|c|}{$\begin{array}{l}\text { TABLE } 3 \\
\text { mputations by amputation levels }\end{array}$} & \multirow{3}{*}{$\begin{array}{c}\text { Within the total of } \\
\text { amputations } \\
\%\end{array}$} \\
\hline & \multicolumn{2}{|c|}{$\begin{array}{c}\text { The level and number of } \\
\text { amputations }\end{array}$} & \multirow[b]{2}{*}{ (n) } & \multirow{2}{*}{$\begin{array}{c}\text { Within single } \\
\text { extremity amputations } \\
\%\end{array}$} & \multirow{2}{*}{$\begin{array}{c}\begin{array}{c}\text { Within multiple } \\
\text { extremity amputations }\end{array} \\
\%\end{array}$} & \\
\hline & Double & Triple & & & & \\
\hline Hip disarticulation & & & 2 & 0.8 & & 0.7 \\
\hline Transfemoral & & & 88 & 34.5 & & 28.7 \\
\hline Knee disarticulation & & & 6 & 2.4 & & 2 \\
\hline Transtibial & & & 85 & 33.3 & & 27.7 \\
\hline Ankle disarticulation & & & 1 & 0.4 & & 0.3 \\
\hline Chopart & & & 9 & 3.5 & & 2.9 \\
\hline Shoulder disarticulation & & & 2 & 0.8 & & 0.7 \\
\hline Transhumeral & & & 20 & 7.8 & & 6.5 \\
\hline Transradial & & & 26 & 10.2 & & 8.5 \\
\hline Wrist disarticulation & & & 7 & 2.7 & & 2.3 \\
\hline Partial hand & & & 9 & 3.5 & & 2.9 \\
\hline Hip disarticulation & Hip disarticulation & & 1 & & 1.9 & 0.3 \\
\hline Transfemoral & Hip disarticulation & & 3 & & 5.8 & 1 \\
\hline Transfemoral & Transfemoral & & 9 & & 17.3 & 2.9 \\
\hline Transtibial & Transfemoral & & 8 & & 15.4 & 2.6 \\
\hline Knee disarticulation & Transtibial & & 3 & & 5.8 & 1 \\
\hline Transtibial & Transtibial & & 10 & & 19.2 & 3.3 \\
\hline Transtibial & Chopart & & 1 & & 1.9 & 0.3 \\
\hline Chopart & Chopart & & 2 & & 3.8 & 0.7 \\
\hline Transhumeral & Transhumeral & & 1 & & 1.9 & 0.3 \\
\hline Transradial & Transhumeral & & 2 & & 3.8 & 0.7 \\
\hline Transradial & Transradial & & 2 & & 3.8 & 0.7 \\
\hline Transradial & Partial hand & & 2 & & 3.8 & 0.7 \\
\hline Transfemoral & Transradial & & 1 & & 1.9 & 0.3 \\
\hline Transtibial & Transradial & & 2 & & 3.8 & 0.7 \\
\hline Transfemoral & Wrist disarticulation & & 1 & & 1.9 & 0.3 \\
\hline Chopart & Partial hand & Partial hand & 1 & & 1.9 & 0.3 \\
\hline Transtibial & Transtibial & Transhumeral & 1 & & 1.9 & 0.3 \\
\hline Transfemoral & Transfemoral & Transhumeral & 1 & & 1.9 & 0.3 \\
\hline Transtibial & Transtibial & Transradial & 1 & & 1.9 & 0.3 \\
\hline
\end{tabular}




\begin{tabular}{|c|c|c|}
\hline \multicolumn{3}{|c|}{$\begin{array}{c}\text { TABLE } 4 \\
\text { The distribution of amputated extremities according to amputation levels }\end{array}$} \\
\hline & $\mathrm{n}$ & $\%$ \\
\hline Hip disarticulation & 7 & 1.9 \\
\hline Transfemoral & 121 & 33.3 \\
\hline Knee disarticulation & 9 & 2.5 \\
\hline Transtibial & 123 & 33.9 \\
\hline Ankle disarticulation & 1 & 0.3 \\
\hline Chopart & 15 & 4.1 \\
\hline Shoulder disarticulation & 2 & 0.6 \\
\hline Transhumeral & 26 & 7.1 \\
\hline Transradial & 38 & 10.5 \\
\hline Wrist disarticulation & 8 & 2.2 \\
\hline Partial hand & 13 & 3.6 \\
\hline Total & 363 & 100 \\
\hline
\end{tabular}

\begin{tabular}{|lccc|}
\multicolumn{5}{c}{ TABLE 5} \\
Etiology and distribution of the amputations by years \\
& $\begin{array}{c}\text { Single extremity } \\
\text { amputation }\end{array}$ & $\begin{array}{c}\text { Multiple extremity } \\
\text { amputation }\end{array}$ & Total \\
\cline { 2 - 3 } & $\%$ & $\%$ & $\%$ \\
\hline Etiology of amputation & & & \\
$\quad$ Firearms & 2 & - & 1.6 \\
Bombing & 87.4 & 98.1 & 89.3 \\
Landmines & 10.2 & 1.9 & 8.8 \\
Terror & 0.4 & - & 0.3 \\
Distribution of the amputations by years & & & \\
$\leq 2012$ & 7.5 & 5.7 & 7.2 \\
2013 & 17.3 & 19.2 & 17.6 \\
2014 & 15.3 & 7.7 & 14.0 \\
2015 & 24.7 & 21.2 & 24.1 \\
2016 & 20.0 & 32.7 & 22.1 \\
2017 & 7.8 & 7.7 & 7.8 \\
2018 & 6.3 & 5.8 & 6.2 \\
\hline
\end{tabular}

Most of the amputations occurred in the period of 2015 and 2016 (Table 5).

\section{DISCUSSION}

It has been reported in regions affected by terror or war, namely Turkey, Iran, Iraq and Pakistan, that the mean age of amputees is low ranging from 17.6 to 29.15 years $^{[8,19-23]}$ and the ratio of male amputees is very high ranging from 87 to $92 \% \cdot{ }^{[19,20,24,25]}$ These studies mostly included the military personnel, which greatly skewed the results toward one direction in terms of age and sex. On the other hand, the mean age of amputations increases in regions where there is no terror or war ( $\geq 36.5$ years $)^{[26-29]}$ and the ratio of male amputees decreases relatively ranging between 75 and $86 \% .^{[27,29-31]}$

In reports by a NGO operating in Syria, it was stated that injured individuals were mostly males $(83 \%)^{[32]}$ and $17 \%$ of were children. ${ }^{[33]}$ Similarly, $18 \%$ of the individuals treated in Turkish hospitals due to Syrian Civil War-related injuries between 2013 and 2014 were reported to be children. ${ }^{[18]}$ The low mean age of the amputees (25.8 years) and the high ratio of the male amputees $(86.6 \%)$ in the present study are compatible with the studies conducted in regions where there was war or terror. ${ }^{[8,19-25]}$ In the present study, the rate of amputees below the age of 18 years (25.4\%) was higher than those of 
other Syrian Civil War-based studies. ${ }^{[18,33]}$ The high rate of child/adolescent amputees in the present study may be associated with the type of the war, i.e., the residential area bombings. These findings indicate that a substantial number of children and adolescents face with the amputation trauma, as well as war-induced trauma and stigma of being a refugee.

In general, war amputations occur in young and healthy individuals. ${ }^{[2,34]}$ which increase the importance of medical and rehabilitation interventions. ${ }^{[12]}$ The desire of active young individuals with high physical conditions to return to the productive lifestyle after amputation imposes a different function on the social support efforts geared toward young civilian amputees. $^{[12]}$ In this study, $23.1 \%$ of the amputees were students in Syria before the war and of whom $10.1 \%$ were able to continue their education after they left the war zone, revealing the magnitude of the need for occupational therapy besides psychological and physical rehabilitation. In addition, most of the amputees were workers or tradesmen, while a very low portion of them were unemployed before the war; however, most of them were unemployed in their new lives away from the war zone. Although support is provided in Turkey for the Syrian refugees to get employed easily, the high rate of unemployment among the amputees, possibly caused by their disability and/or refugee status, increases the magnitude of the trauma they experience. Those residing in refugee camps cannot possibly be employed due to conditions in the camps. This finding highlights the importance of the need for unorthodox approaches by the international aid organizations in the long run toward issues, such as employment problems faced by the Syrian refugee amputees.

The low rate of chronic diseases in the present study is a natural outcome of the low mean age of the amputees. However, a very high rate of young amputees in the present study indicates the immense need for prosthesis and orthosis by these individuals in the future which, in turn, highlights the need for a careful planning in this regard.

In studies including United States (US) and United Kingdom (UK) military personnel in various war zones, LEA rates have been reported between 77.5 and $86 \% .^{[10,23,35,36]}$ The rate of unilateral LEAs induced by traumatic injuries during the Iran-Iraq War was also reported to be high (84\%). ${ }^{[22]}$ In a study carried out 20 years after the Bosnia-Herzegovina War, where civilians were heavily targeted, amputation was needed in $83.3 \%$ of the individuals injured by landmines and most of these amputations $(85.7 \%)$ involved the lower extremities. ${ }^{[13]}$ In another study, $56 \%$ of the injuries induced by the Syrian Civil War involved extremities. ${ }^{[17]}$ In the global Handicap International (HI) report, it was estimated that amputation was needed in $15 \%$ of the injuries induced by explosive weapons. ${ }^{[33]}$ In the present study, the rate of LEAs was found to be higher, compared to a study reporting that the rate of amputations occurred in Syrian Civil War-related injuries was $54.5 \%{ }^{[24]}$ The reasons for the difference may be the fact that the amputees in the present study were from a wider residential area and the other study included rate only from the period between 2012 and 2015. On the other hand, the rate of single extremity amputations in the present study (74.9\%) is lower than that of LEAs occurred in other war zones, including the Bosnia-Herzegovina War. ${ }^{[10,13,23,35,36]}$ In studies including Pakistani military personnel, terror victims in Turkey, and UK/US military personnel in the Iraq and Afghanistan Wars and veterans from the Iraq-Iran War, LEAs have widely been reported and TTA appears to be the most common amputation level reported in these studies (34.6 to $60.9 \%))^{[3,10,19,21,23,35]}$ In few studies, on the other hand, TFA has been reported to be the most common amputation level (27 to 55\%). ${ }^{[35,37]}$ In civilian amputations occurred in the Bosnia-Herzegovina War, TTA was reported to be $65.7 \%{ }^{[13]}$ In the present study, the rates of TFA and TTA were found to be close, which is a noteworthy difference of the present study compared to the results of previous studies. This outcome is considered as a result of the heavy damage caused by the bombardment methods used in the Syrian Civil War. Landmines used in war zones or in residential areas such as Bosnia-Herzegovina cause foot or TTAs, whereas bombings cause wider injuries in upper parts.

In a study in which only the upper extremity amputations (UEAs) were examined, most of the UEAs occurred in the US military personnel in a 10-year time period were transradial amputations (TRAs). ${ }^{[34]}$ On the other hand, in another study, transhumeral amputation (THA) was reported to be the most common amputation level in the US military personnel fought in Iraq and Afghanistan ${ }^{[35]}$ and also in the UK military personnel. ${ }^{[23]}$ In the Bosnia-Herzegovina War, in which the civilians were targeted, UEAs were reported to be lower than LEAs. ${ }^{[13]}$ In this study, the upper UEA rate $(24.1 \%)$ was also higher than that of previous studies from other war zones. ${ }^{[13]}$ The high rate of TRAs among the 
Syrian Civil War victims reported in this study is similar to the results by Tennent et al. ${ }^{[34]}$ however, it contradicts with other studies. ${ }^{[13,23,35]}$

Lower extremities are more susceptible to trauma, as it maintains the relationship between the body and the ground. In war conditions, damages on lower extremities caused by ground-launched explosives are inevitable. ${ }^{[10]}$ Landmines usually cause foot or TTAs and they cause relatively less damage. Bombs, on the other hand, may cause greater damage on extremities or the body, and they cause amputations involving knee or hip joints due to their direct damages, as well as due to the damages caused by the secondary effects of the damaged structures. ${ }^{[10]}$

In previous wars where civil casualties were mostly caused by landmines, the UEA rates were also relatively low. Although an extra-effort is put to save upper extremities due to the insufficiency of the upper extremity prostheses in mimicking human joint functions, ${ }^{[10]}$ the high rate of UEAs in this study is noteworthy. In regular wars, the skills of military hospitals for war surgeries result in better abilities in attaining minimal amputations, which cannot be maintained in the Syrian Civil War and, thus, UEAs were observed more in the Syrian Civil War. In this respect, again, the Syrian Civil War is different from other wars of the century.

Multiple extremity amputations in the World War I and Korean War were 2 to $8 \%^{[10]}$ and multiple LEAs were reported to be higher (18 to 47\%) among US military personnel during the Vietnam and Iraq-Afghanistan Wars and in UK military personnel deployed in various war zones. ${ }^{[10,23,35,37]}$ This rate among the Turkish military personnel subjected to terrorist attacks was reported to be $13 \%{ }^{[19]}$ and it was lower (3.5 to 6.5\%) among the Pakistani military personnel and also among Iran-Iraq War veterans. ${ }^{[21,22]}$ It was reported that bilateral UEA rates ranged between 5 and 5.7\% in Iraq and Afghanistan Wars. ${ }^{[10,35]}$

Multiple amputation rate was found to be high in the present study (16.9\%). The most common multiple amputations involved lower extremities. Bilateral TTAs and TFAs were the most common amputation levels with similar rates. The rate of multiple amputations involving only bilateral upper extremities was found to be $15.4 \%$ of all multiple amputations. With developing technologies, the damaging capabilities of the explosives have been dramatically increased, resulting in an increased rate of mortal bodily injuries. On the other hand, improvements in protective measures and the faster and easier access to surgery centers in battlefields increased the survival rate of mortal extremity injuries by amputation. ${ }^{[6,10]}$ The increase in the rate of multiple amputation in parallel with the greater access of war technologies supports this hypothesis. The scarcity of hospitals and surgeons in Syria increased the rate of extremity amputations in cases where the extremity could have been saved. Furthermore, bombings of the residential areas in the Syrian Civil War caused substantial damages in buildings, which might have increased the rate of multiple extremity amputations. In the present study, the most common cause of multiple amputations was found to be bombing (98.1\%), which supports this hypothesis. In 2016, the rate of multiple amputations dramatically increased parallel with the intensity of the war. The higher number of single individuals in the multiple amputation group may be associated with their relatively lower mean age.

In the US army deployed in various regions in the world, major amputations were reported to be caused by explosive mechanisms such as landmines (87.9 to $97 \%),{ }^{[7,8,10,34-37]}$ which was followed by gunshot wounds (3.7 to $4.7 \%$ ) and a very low number of amputations were caused by motorized vehicle accidents. ${ }^{[10,34,35]}$

In terror/trauma-induced amputations occurred in Turkey, landmines were reported to be the primary cause (92.7\%). ${ }^{[19]}$ Lower extremity amputations in Pakistani army were mainly caused by traumas (96.7\%) and the most common cause was reported to be landmines (59.7\%). ${ }^{[21]}$ The most common cause of amputations in the Iran-Iraq War was also landmines (61 to 66.6\%) and explosives devices (bombs) (23.4 to $25.9 \%$ ), and the gunshot wounds (7.41 to $15.6 \%$ ) were also reported among the common causes. ${ }^{[22,33]}$ In another study investigating the amputations occurred due the Iran-Iraq War, shells (50\%) and landmines (34\%) were reported as the major causes, whereas bombings, as a cause of amputation, were reported to be lower (9\%). ${ }^{[38]}$ In Bosnia-Herzegovina War-related amputations, landmines were found to be the leading cause. ${ }^{[13]}$ At the beginning of the Iraq War, mainly due to the bombings by airstrikes and suicide attacks, civilian casualties were reported to be much more than military casualties. ${ }^{[39]}$

In 2012, mostly males (91.4\%) were killed in the Syrian Civil War and the leading cause of death was reported as explosives and shrapnel injuries (67.2\%), followed by gunshot wounds (26.3\%). ${ }^{[14]}$ In another study including only children in the Syrian 
Civil War, causes of death were reported as $70 \%$ bombing and shrapnel injuries and $13.6 \%$ gunshot wounds. ${ }^{[15]}$ In Syrian Civil War-related injuries treated in Turkey, gunshot injury was found to be $70.1 \%$ in $2011-2012^{[16]}$ and $64.4 \%$ in 2012-2013, whereas gunshot injury was $3 \%$, landmines was $5 \%$, and bombings and other exclusives were 92\% in 2012-2015 in the same region. ${ }^{[24]}$ In another study in which the substantial numbers of children (18\%) were reported as injured during the Syrian Civil War in 2013-2014, blunt trauma (55\%) was the main mechanism of injury, although it was also reported that more brutal methods, such as firearms, were also used against children (7.2\%). ${ }^{[18]}$ In the 2016 report of HI, operating in Jordan and Lebanon as well as the northern Syria, mechanisms of injury were listed as explosive weapons ( $45.6 \%$ bombs and $7.4 \%$ landmines), gunshot (20\%), and accidents (14\%). ${ }^{[33]}$ In the Syrian Civil War, although gunshot injuries occurred frequently in the beginning, bombing-induced amputations increased later on. In the present study, the main cause of amputations was found to be bombings (89.3\%), which contradicts with the studies including mainly military personnel ${ }^{[3,7,8,19,21,22,35]}$ as well as those including civilians. ${ }^{[13]}$ Although the reasons for amputation in the present study were different from the ones reported in studies regarding the early years of the Syrian Civil War, ${ }^{[16,17]}$ they were similar to those included in analyses made later. ${ }^{[24]}$ The reason for the low rates of landmines among the causes of amputation may be due to demining process previously carried out by Turkey. When the progress of the war is considered, a change in the characteristics of the Syrian Civil War is obvious. In a research by the HI investigating the Syrian Civil War longitudinally, injuries caused by gunshot wounds were reported to be $20 \%{ }^{[33]}$ At the onset of the war, gunshot wounds were caused by snipers in regions dominated by terrorist organizations, ${ }^{[16,17]}$ but later such injuries were reported to be decreased. ${ }^{[24]}$ The lower rate of gunshot wounds in the present study agrees with recent studies. ${ }^{[24]}$ During the course of the war, bombings by various governments or terrorist organizations and targeting mostly the civilian regions increased. This outcome also supports the idea that the Syrian Civil War presents quite a different picture in terms of the injury-amputation profile, compared to other wars targeting mostly the civilians. The Syrian Civil War is a war in which civilians were injured mostly due to bombings. In the present study, the majority of the amputees were amputated in the period of 2015-2016, which illustrates the gunshot-to-bombing transition.
Nonetheless, there are some limitations to this study. In this study, database of an NGO was used in Turkey, but restricting the access to the amputees in Syria due to the security concerns, it was not possible to obtain a sampling representing the Syria population. Furthermore, those amputees who already had a prosthesis and did not need to change it did not visit these centers and, thus, the sample partially represented the universe.

In conclusion, Syrian Civil War is the first war in which bombing is the most frequent factor causing civilian amputations. Syrian Civil War displays a different profile compared to other civil wars to date with too many adolescent/children amputations and with surprisingly a high number of UEAs and multiple amputations.

\section{Acknowledgment}

We would like to thank to Zehra Akpınar and Zeynep Söyler for contribution to data gather process.

Declaration of conflicting interests

The authors declared no conflicts of interest with respect to the authorship and/or publication of this article.

Funding

The authors received no financial support for the research and/or authorship of this article.

\section{REFERENCES}

1. Ziegler-Graham K, MacKenzie EJ, Ephraim PL, Travison TG, Brookmeyer R. Estimating the prevalence of limb loss in the United States: 2005 to 2050. Arch Phys Med Rehabil 2008;89:422-9.

2. Aboutanos MB, Baker SP. Wartime civilian injuries: epidemiology and intervention strategies. J Trauma 1997;43:719-26.

3. Taghipour H, Moharamzad Y, Mafi AR, Amini A, Naghizadeh MM, Soroush MR, et al. Quality of life among veterans with war-related unilateral lower extremity amputation: a long-term survey in a prosthesis center in Iran. J Orthop Trauma 2009;23:525-30.

4. Mazurek MT, Ficke JR. The scope of wounds encountered in casualties from the global war on terrorism: from the battlefield to the tertiary treatment facility. J Am Acad Orthop Surg 2006;14:S18-23.

5. Owens BD, Kragh JF Jr, Wenke JC, Macaitis J, Wade CE, Holcomb JB. Combat wounds in operation Iraqi Freedom and operation Enduring Freedom. J Trauma 2008;64:295-9.

6. Clasper J, Ramasamy A. Traumatic amputations. Br J Pain 2013;7:67-73.

7. Coupland RM, Howell PR. An experience of war surgery and wounds presenting after 3 days on the border of Afghanistan. Injury 1988;19:259-62.

8. Soroush A, Falahati F, Zargar M, Soroush M, Khateri S, Khaji A. Amputations due to landmine and unexploded ordinances in post-war Iran. Arch Iran Med 2008;11: 595-7. 
9. Doukas WC, Hayda RA, Frisch HM, Andersen RC, Mazurek MT, Ficke JR, et al. The Military Extremity Trauma Amputation/Limb Salvage (METALS) study: outcomes of amputation versus limb salvage following major lowerextremity trauma. J Bone Joint Surg [Am] 2013;95:138-45.

10. Stansbury LG, Lalliss SJ, Branstetter JG, Bagg MR, Holcomb JB. Amputations in U.S. military personnel in the current conflicts in Afghanistan and Iraq. J Orthop Trauma 2008;22:43-6.

11. McFarland LV, Hubbard Winkler SL, Heinemann AW, Jones M, Esquenazi A. Unilateral upper-limb loss: satisfaction and prosthetic-device use in veterans and servicemembers from Vietnam and OIF/OEF conflicts. J Rehabil Res Dev 2010;47:299-316.

12. Farrokhi S, Mazzone B, Eskridge S, Shannon K, Hill OT. Incidence of Overuse Musculoskeletal Injuries in Military Service Members With Traumatic Lower Limb Amputation. Arch Phys Med Rehabil 2018;99:348-354.e1.

13. Ryken KO, Hogue M, Marsh JL, Schweizer M. Long-term consequences of landmine injury: A survey of civilian survivors in Bosnia-Herzegovina 20 years after the war. Injury 2017;48:2688-92.

14. Çelikel A, Karaarslan B, Demirkıran DS, Zeren C, Arslan MM. A series of civilian fatalities during the war in Syria. Ulus Travma Acil Cerrahi Derg 2014;20:338-42.

15. Çelikel A, Karbeyaz K, Kararslan B, Arslan MM, Zeren C. Childhood casualties during civil war: Syrian experience. J Forensic Leg Med 2015;34:1-4.

16. Karakuş A, Yengil E, Akkücük S, Cevik C, Zeren C, Uruc V. The reflection of the Syrian civil war on the emergency department and assessment of hospital costs. Ulus Travma Acil Cerrahi Derg 2013;19:429-33.

17. Hakimoglu S, Karcioglu M, Tuzcu K, Davarcı I, Koyuncu $\mathrm{O}$, Dikey İ, et al. Assessment of the perioperative period in civilians injured in the Syrian Civil War. Braz J Anesthesiol 2015;65:445-9.

18. Er E, Çorbacıoğlu ŞK, Güler S, Aslan Ş, Seviner M, Aksel G, et al. Analyses of demographical and injury characteristics of adult and pediatric patients injured in Syrian civil war. Am J Emerg Med 2017;35:82-6.

19. Yaşar E, Tok F, Kesikburun S, Ada AM, Kelle B, Göktepe $\mathrm{AS}$, et al. Epidemiologic data of trauma-related lower limb amputees: A single center 10-year experience. Injury 2017;48:349-52.

20. Moini M, Rasouli MR, Khaji A, Farshidfar F, Heidari P. Patterns of extremity traumas leading to amputation in Iran: results of Iranian National Trauma Project. Chin J Traumatol 2009;12:77-80.

21. Rathore FA, Ayaz SB, Mansoor SN, Qureshi AR, Fahim M. Demographics of lower limb amputations in the pakistan military: A single center, three-year prospective survey. Cureus 2016;8:e566.

22. Ebrahimzadeh MH, Rajabi MT. Long-term outcomes of patients undergoing war-related amputations of the foot and ankle. J Foot Ankle Surg 2007;46:429-33.

23. Dharm-Datta S, Etherington J, Mistlin A, Rees J, Clasper J. The outcome of British combat amputees in relation to military service. Injury 2011;42:1362-7.
24. Karakus A, Kuvandik G, Atalay E. Evaluation of extremity injuries presented to emergency department. Arch Iran Med 2017;20:646-8.

25. Spiegel PB, Salama P. War and mortality in Kosovo, 199899: an epidemiological testimony. Lancet 2000;355:2204-9.

26. Dillingham TR, Pezzin LE, MacKenzie EJ. Incidence, acute care length of stay, and discharge to rehabilitation of traumatic amputee patients: an epidemiologic study. Arch Phys Med Rehabil 1998;79:279-87.

27. KobayashiL, Inaba K, Barmparas G, Criscuoli M, Lustenberger T, Talving P, et al. Traumatic limb amputations at a level I trauma center. Eur J Trauma Emerg Surg 2011;37:67-72.

28. Asplund M, Nilsson M, Jacobsson A, von Holst H. Incidence of traumatic peripheral nerve injuries and amputations in Sweden between 1998 and 2006. Neuroepidemiology 2009;32:217-28.

29. Unwin N. Epidemiology of lower extremity amputation in centres in Europe, North America and East Asia. Br J Surg 2000;87:328-37.

30. Low EE, Inkellis E, Morshed S. Complications and revision amputation following trauma-related lower limb loss. Injury 2017;48:364-70.

31. Inkellis E, Low EE, Langhammer C, Morshed S. Incidence and characterization of major upper-extremity amputations in the national trauma data bank. JB JS Open Access 2018;3:e0038.

32. Handicap International. Everywhere the bombing followed us: Forced displacement and the use of explosive weapons in populated areas. Perspectives of Syrian women refugees in Lebanon. Study 2017 Advocacy of Handicap International. Available at: https://www.unhcr. org/5a86aa607.pdf [Accessed: September, 2017].

33. Handicap International, 'Syria, a mutilated future: A focus on the persons injured by explosive weapons', (May 2016). Available at: http://www.inew.org/site/ wpcontent/ uploads/2016/06/Factsheet_Syria_2016_FINAL.pdf.

34. Tennent DJ, Wenke JC, Rivera JC, Krueger CA. Characterisation and outcomes of upper extremity amputations. Injury 2014;45:965-9.

35. Krueger CA, Wenke JC, Ficke JR. Ten years at war: comprehensive analysis of amputation trends. J Trauma Acute Care Surg 2012;73(6 Suppl 5):S438-44.

36. Belmont PJ Jr, McCriskin BJ, Hsiao MS, Burks R, Nelson KJ, Schoenfeld AJ. The nature and incidence of musculoskeletal combat wounds in Iraq and Afghanistan (2005-2009). J Orthop Trauma 2013;27:e107-13.

37. Staruch RM, Jackson PC, Hodson J, Yim G, Foster MA, Cubison $\mathrm{T}$, et al. Comparing the surgical timelines of military and civilians traumatic lower limb amputations. Ann Med Surg (Lond) 2016;6:81-6.

38. Ebrahimzadeh MH, Moradi A, Khorasani MR, HallajMoghaddam M, Kachooei AR. Long-term clinical outcomes of war-related bilateral lower extremities amputations. Injury 2015;46:275-81.

39. Hicks MH, Dardagan H, Bagnall PM, Spagat M, Sloboda JA. Casualties in civilians and coalition soldiers from suicide bombings in Iraq, 2003-10: a descriptive study. Lancet 2011;378:906-14. 